\title{
Communicating about prognosis with regard to osteosarcoma in a South African cross-cultural clinical setting: strategies and challenges
}

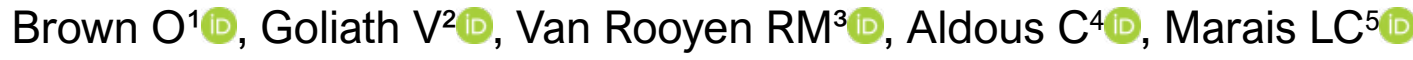 \\ 1 PhD; Clinical Psychologist, School of Clinical Medicine, University of KwaZulu-Natal, South Africa \\ 2 PhD; Associate Professor, Department of Social Development Professions, Nelson Mandela University, South Africa \\ 3 MCur, PhD; Professor and Deputy Dean of the Faculty of Health Sciences, School of Clinical Care Sciences, Nelson Mandela University, South Africa \\ $4 \mathrm{PhD}$; Professor and Health Care Scientist in the School of Clinical Medicine, University of KwaZulu-Natal, Durban, South Africa \\ 5 MBChB, FC(Orth)SA, MMed(Ortho), CIME, PhD; Professor and Head of the Department of Orthopaedics, University of KwaZulu-Natal, Durban, \\ South Africa
}

Corresponding author: Dr Ottilia Brown, The LightHouse Arabia, 821 Al Wasl Road, Al Safa 2, Dubai; tel: +971 50 4601346;

email: ottiliabrown1978@gmail.com

\begin{abstract}
Background: Effective prognostic communication with patients is a prerequisite for treatment decision-making, yet it is a difficult task to manage with confidence. This paper explores the strategies used and challenges faced when communicating about prognosis in a cross-cultural clinical setting.

Patients and methods: We used a qualitative exploratory descriptive contextual design and gathered data using focus group interviews with healthcare professionals. Twenty-three healthcare professionals participated in three focus groups. We analysed the data thematically. Guba's Model of Trustworthiness was used to ensure rigour.

Results: Our findings revealed strategies for communicating about prognosis. Assessing patient emotions and knowledge, and providing patients with clear prognostic information, emerged as prominent strategies. Healthcare professionals proposed communicating frankly about the consequences of not treating osteosarcoma, treatment limitations, metastases and poor prognoses. They also suggested presenting prognostic information in a staged approach, normalising death, and not specifying life expectancy. In addition, informing patients that a palliative amputation would help with pain management emerged as a strategy for instilling hope. Various patient, provider and disease factors were identified as challenges when discussing prognosis.

Conclusions: Deviations from Western research findings emphasised the need for studies exploring prognostic communication in cross-cultural encounters. Our study highlighted the need for creative and thoughtful approaches to communicating sensitive information in cross-cultural clinical settings.
\end{abstract}

Level of evidence: Level 5

Keywords: prognosis, patient-provider communication, cancer, osteosarcoma, cross-cultural

Citation: Brown O, Goliath V, Van Rooyen RM, Aldous C, Marais LC. Communicating about prognosis with regard to osteosarcoma in a South African cross-cultural clinical setting: strategies and challenges. SA Orthop J 2019;18(4):46-51. http://dx.doi.org/10.17159/2309-8309/2019/v18n4a6

Editor: Prof TLB le Roux, University of Pretoria, South Africa

Received: March 2019

Accepted: April 2019

Published: November 2019

Copyright: () 2019 Brown O, et al. This is an open-access article distributed under the terms of the Creative Commons Attribution Licence, which permits unrestricted use, distribution and reproduction in any medium, provided the original author and source are credited.

Funding: There are no funding sources to declare.

Conflict of interest: All authors confirm that there are no conflicts of interest to declare. 


\section{Introduction}

Effective prognostic communication with patients is a prerequisite for treatment decision-making and future planning that is commensurate with patient preferences. ${ }^{1}$ However, communicating about prognosis is widely documented as a challenging task. ${ }^{2-5}$ Patients typically have varied preferences regarding prognosis information ${ }^{6}$ that are sometimes complicated by cultural and family expectations and demands. ${ }^{5}$ In addition, the medical literature provides conflicting directives. Some studies indicate that patients want and need detailed information, and other studies report that patients want to limit their discussions about poor prognoses. ${ }^{2}$

This study was conducted with healthcare professionals working in a cross-cultural clinical setting in KwaZulu-Natal, South Africa. The study is part of a larger project aimed at developing an evidence-based practice guideline for communicating with Zulu patients diagnosed with osteosarcoma. The Zulu people are indigenous and place great value on traditional belief systems and often prefer a family-centred model of medical decisionmaking ${ }^{5}$ especially when the proposed surgical treatment option is amputation. ${ }^{7}$ A 2012 study revealed that $66.67 \%$ of the patients presenting at the study site with osteosarcoma between 2009 and 2011 already had metastatic disease. ${ }^{8}$ Healthcare professionals (HCPs) therefore find communicating prognosis to be especially challenging in this cross-cultural context as patients present late for treatment and tend to practise systems of healing and decisionmaking that are different from the Western medical system.

Prognostic communication literature provides some guidelines for healthcare professionals. A patient-centred approach,, 910 a staged approach, ${ }^{11}$ respect for patients' occasional preference to maintain some ambiguity about the future,${ }^{6}$ and responding to varied prognostic information needs between individuals and for a given individual over time,${ }^{5}$ are recommended strategies. Further, a need for detailed information may still include negotiation regarding the extent, format and timing of the information received. ${ }^{3}$ Given the late presentation of patients at the study site, these proposed strategies may not be tenable as HCPs have to communicate diagnostic and treatment information urgently. The treatment options are closely related to patients' understanding of their prognosis and the outcomes resulting from various approaches to treatment. This paper explores the strategies used and challenges faced when communicating about prognosis in this cross-cultural clinical setting.

\section{Methods}

\section{Study setting}

This study was conducted at a tertiary hospital in the province of KwaZulu-Natal (KZN), South Africa. The hospital forms part of the national public health system that serves more than $80 \%$ of the South African population. The majority of the patients receiving services at this hospital are of Zulu origin. Zulu patients speak isiZulu, one of South Africa's 11 official languages, while healthcare professionals mostly speak English or Afrikaans. The hospital's Tumour, Sepsis and Reconstruction Unit (TSR), dedicated to the treatment of musculoskeletal tumours, is the only one of its kind in western $\mathrm{KZN}$ and services a population of 3.5 million people.

\section{Research design and methods}

A qualitative exploratory descriptive contextual design was used. We gathered data from three separate focus group interviews with orthopaedic consultants and registrars; allied health professionals including dieticians, occupational therapists, physiotherapists, and a social worker; and nurses from the orthopaedic and oncology outpatient clinics and wards. The focus group interview schedule was piloted with a social work colleague who has experience with working with cancer patients in the study setting. Questions explored how HCPs discuss prognosis with patients and also investigated how HCPs responded to questions from patients regarding prognosis if they chose not to discuss prognosis with patients.

\section{Participants and sampling}

The TSR Unit uses a multidisciplinary team (MDT) approach to managing patients diagnosed with osteosarcoma. The MDT comprises the orthopaedic consultants and registrars, the allied health professionals (physiotherapists, dieticians, occupational therapists, social workers, clinical psychologists) and orthopaedic and oncology nursing staff. We used census sampling and invited all these members of the MDT to participate in the focus groups. Twenty-three HCPs participated (see Table I) and five were not available due to scheduling constraints. Four Zulu healthcare professionals participated in the study, thus emphasising the fact that medical encounters are largely culturally discordant at this tertiary hospital.

\begin{tabular}{ll}
\hline $\begin{array}{l}\text { Table I: Focus group demographic information ( } \mathrm{n}=23) \\
\text { Orthopaedic consultants and registrars }\end{array}$ & $\mathrm{n}=9$ \\
\hline $\begin{array}{l}\text { Registered nurses from orthopaedic wards, orthopaedic } \\
\text { clinic, oncology clinic and pain service }\end{array}$ & $\mathrm{n}=5$ \\
\hline $\begin{array}{l}\text { Allied health professionals (physiotherapists, occupational } \\
\text { therapists, dieticians, social worker) }\end{array}$ & $\mathrm{n}=9$ \\
\hline $\begin{array}{l}\text { Sex } \\
\text { Males }\end{array}$ & \\
$\begin{array}{l}\text { Females } \\
\text { Ethnic group (South Africa) }\end{array}$ & $\mathrm{n}=8$ \\
$\begin{array}{l}\text { White } \\
\text { Indian }\end{array}$ & $\mathrm{n}=15$ \\
$\begin{array}{l}\text { African (Zulu) } \\
\text { Coloured }\end{array}$ & $\mathrm{n}=13$ \\
& $\mathrm{n}=4$ \\
$\mathrm{n}=4$ \\
$\mathrm{n}=2$
\end{tabular}

\section{Data collection, analysis and trustworthiness}

The second author, an independent researcher with qualitative expertise and with no prior knowledge of the participants, conducted the focus group interviews. The interviews' duration ranged from 54 to 95 minutes and were audiotaped and transcribed verbatim. We used thematic analysis to analyse the data. ${ }^{12}$ The primary researcher and the focus group interviewer independently coded the data, and themes were then discussed and agreed upon. Themes were further independently reviewed by two qualitative research experts and finalised following multiple discussions with all three qualitative experts. The data analysis process was an iterative one. Guba's Model of Trustworthiness was used to ensure the rigour of the data collection and analysis processes. ${ }^{13,14}$

\section{Ethical approval and considerations}

We obtained ethical approval for the study from the Biomedical Research Ethics Committee at the University of KwaZulu-Natal. Participation was voluntary, and written informed consent was obtained from all participants.

\section{Results}

The findings highlighted the specific strategies used and challenges encountered when discussing prognosis with Zulu 
patients diagnosed with osteosarcoma. Participants reflected on the transformative nature of the focus groups ${ }^{15}$ as it created an opportunity for reflection on practice, and co-construction of culturally relevant strategies for communicating prognosis.

\section{Strategies for managing the prognostic discussion}

\section{Strategy 1: Assess patient emotions and knowledge}

HCPs indicated that they first enquired about patients' thoughts, fears and impressions of the future.

I try to first find out what are their thoughts, what are they scared about, what are they feeling is going to happen and patients do know, especially prognosis, they do know when the end is near...

\section{Strategy 2: Provide patients with realistic prognostic information}

The late presentation of patients and additional time required for cultural practices meant that HCPs had to share prognostic information urgently in order to fast-track treatment decisionmaking.

\section{Strategy 2.1: Inform patients about the prognostic consequences of not treating osteosarcoma}

HCPs informed patients that if left untreated, the cancer would metastasise, and the patient would not survive. Patients requiring amputation typically requested to go home to consult traditionally and perform rituals if indicated, thus causing treatment delays. HCPs were therefore especially direct with these patients. Participants sometimes phrased this discussion by informing patients that if nothing was done it would be detrimental but if the amputation was done there was a chance of survival.

I tell them that if left untreated it can spread and it will kill you.

I am saying if we do nothing it's bad, if you do something there is a chance of a good result.

\section{Strategy 2.2: Inform patients about treatment limitations}

Participants informed patients about treatment limitations. They explained the nature of osteosarcoma to patients and informed patients that this type of cancer was not curable. Participants cautioned against telling patients that amputation could cure due to the possibility of recurrence.

And then I typically explain that this cancer is not curable ... osteosarcoma ... if you leave it untreated it will kill you ...

Participants reported that they informed patients that even with surgery the cancer could recur. HCPs reiterated that patients had to return within six months and then annually to check for cancer recurrence.

... it might spread later, you know even if we take it out now and we do an amputation now it does not mean that the cancer can't come back.

\section{Strategy 2.3: Inform patients that they have metastases}

When patients had metastases, HCPs informed them that the condition was not curable, but that amputation could help with pain.
Patients were informed that limited intervention was possible due to the metastases.

... if we know that it's a metastatic disease and it is not curable to tell them that it has spread already, we can do something about the pain that they have in the leg and the amputation will help for that pain for example, but it has already spread and we can't do much about that.

\section{Strategy 2.4: Inform patients about a poor prognosis}

HCPs highlighted being honest with patients about the terminal nature of the disease if the osteosarcoma was reasonably expected to result in the death of the patient within a short period of time. The time period was not specified.

I personally do tell people if they have a terminal disease that it's so ...

\section{Strategy 3: Use a staged approach}

Some of the allied health participants indicated that they dealt with prognosis in stages because the condition entailed long-term treatment. They focused on immediate goals and if the disease progressed, goals were adjusted to maintenance or palliative care.

I would deal with it in phases because as we said it is a longterm treatment and we are going to wait and see. For now, your issue is this, so our goals will be this. If it becomes worse, then we are going to change our goals to either maintenance or palliative care.

\section{Strategy 4: Normalise death}

Participants approached talking to patients about dying by trying to normalise death as universal to everyone. Participants indicated that they could not specify when the patient would die and sometimes stated that it could be a long time and that they could die from something else as well.

... I can drive out of the hospital and you know get into an accident and die and you may still survive for quite a long time after that, so everyone is going to die ...

\section{Strategy 5: Do not specify a time frame}

Participants emphasised that patients should never be informed of their life expectancy. Some participants indicated that they would not know how to respond to a question about life expectancy.

I never tell them what the life expectancy is.

\section{Challenges related to communicating about prognosis}

During the strategy discussion, HCPs highlighted a number of challenges that they did not know how to resolve. These challenges are described in terms of patient, disease, healthcare provider and communication factors.

\section{Patient factors}

HCPs reported that patients' emotional responses varied from being in denial to being overly optimistic. Participants were also concerned that patients would view treatment as futile when they were informed of poor prognoses. They had experienced that informing a Zulu patient about a poor prognosis often resulted in these patients not returning to the hospital. HCPs hypothesised that this was possibly due to patients believing that they were going to 
die regardless. Participants also experienced that patients stopped listening when they were informed of poor prognoses.

... of course some patients are in denial, some patients are overly optimistic ...

... once we start saying no you are going to die because of cancer then they are not going to come back to you.

Participants observed that patients did not ask about prognosis and indicated that some patients may not want prognostic information. Participants also noted that they would want to know the odds of surviving but that Zulu patients had never asked them about the odds of survival.

... you know if someone tells me okay you have got cancer, it hasn't spread, if we do an amputation that is potentially curative, my thing will be okay what's the chances of that being curative? You know that would be my first question. So, what are my odds? No one has ever asked me that.

\section{Healthcare provider factors}

Competency concerns and lack of training regarding communicating about prognosis were reported. Allied health professionals experienced that there was unclear communication of prognostic information.

From a physio side it can be a bit difficult when patients ask you am I going to die from this ... whereas not being fully medically trained in that aspect we can't always answer those questions for patients.

... the problem is nobody tells you, say this and then say that ...

Certain role expectations emerged among the HCPs with regard to who should communicate with patients regarding prognosis. Nurses were of the opinion that it was ethical procedure for doctors to communicate the prognosis to patients. They indicated that they often interpreted prognostic information for doctors.

... call the doctors and they would explain ...

... you always let the doctor tell the patient the prognosis but we're always standing there ...

HCPs had varied perspectives regarding discussing prognosis with patients. Some were of the opinion that patients should determine how much they wanted to know. Other participants were unsure of whether to disclose poor prognoses. They were concerned that informing patients accordingly could be adding to the bad news of the diagnosis and result in loss of hope. Some HCPs expressed discomfort about talking about prognosis whereas others felt that they would be withholding the truth if they did not inform patients about a poor prognosis. Discussing prognosis was especially challenging when HCPs had to inform patients requiring a palliative amputation as despite the amputation, they would still have limited life expectancy. They were guarded as they did not want to create false hope.

I know there are some people that would say you mustn't tell people if they are terminally ill, that they are going to die.

I don't feel comfortable talking about prognosis ...

I find prognosis being the most difficult one to deal with when they say for a palliative amputation ...

HCPs reported struggling with the timing of the prognostic communication. Zulu patients often insisted on going home to consult with the elders and perform rituals after being informed about treatment options, especially when this entailed amputation. ${ }^{7}$ Participants were concerned that when patients went home, they would be preoccupied with being told about a poor prognosis instead of focusing on consulting the decision-makers regarding proposed treatment options.

You know as soon as they get home they say, the doctor said I am going to die. And then eventually even if the decisionmaker at home or the family sits down and asks about the options, the (patient) keeps saying no, I am going to die ... the doctor told me. (The patient) is now against whatever they (the family) are saying.

\section{Disease factors}

Allied health professionals reported on the unpredictable and aggressive nature of osteosarcoma and its progression, and the consequent challenges of discussing prognosis. They indicated that treatment could start with rehabilitation and dealing with functional issues which then progress to palliative care very quickly.

In my view of prognosis ... I don't know that it can be discussed with the patient because it is an osteosarcoma, it can change from the one stage to the other very quickly ...

\section{Discussion}

The data revealed several strategies for managing the prognostic discussion with Zulu patients and highlighted several challenges that HCPs were not able to resolve. Due to the late presentation of patients at the study site, HCPs felt compelled to communicate the urgency of treatment with patients and this typically included communicating prognostic information. Despite the uniqueness of the setting and participants' competency and training concerns, all the proposed strategies have been supported in the literature.

HCPs recommended assessing patient emotions and knowledge by asking them open-ended questions. ${ }^{2}$ They then advocated that patients should receive realistic information about the prognostic consequences of not treating the osteosarcoma, treatment limitations, metastases, and poor prognoses. This strategy, referred to as realism, can facilitate sound medical decision-making for both patients and HCPs. ${ }^{9}$ However, taking the realistic approach without structuring the conversation and demonstrating empathy can be perceived as being uncaring. ${ }^{9}$ Participants reported that they attempted to phrase information positively.

Participants also proposed the strategy of normalising death. A willingness to talk about death and doing so in a skilful manner without fear has been emphasised.16,17 Participants preferred not to communicate estimations of life expectancy, which is in line with general practice ${ }^{18}$ and clinical practice guidelines on communicating prognosis. ${ }^{19}$

The allied health professionals proposed a staged approach to communicating prognosis. ${ }^{9,11,19,20}$ The late presentation for treatment at this study site ${ }^{8}$ unfortunately presents HCPs with the challenging task of communicating diagnosis, treatment and prognosis in close succession or simultaneously. A staged approach may be more useful for patients that present with localised or minimally metastasised disease.

The strategy of instilling hope did not overtly emerge from the data. However, participants' tendency to inform patients that a palliative amputation would help with pain management has been described as a means of instilling hope. ${ }^{21}$ Patients have reported that when HCPs emphasised what could be done, such as pain and symptom control, this fostered hope. ${ }^{21,22}$ Hope, therefore, is not exclusively dependent on cure $^{2}$ and should be offered at all stages of the disease..$^{23,24}$

Participants also reported experiencing challenges pertaining to the prognostic communication process. They highlighted Zulu patients' emotional responses, their beliefs that treatment would be futile and their tendency to withdraw when poor prognoses were communicated. These reported responses may be associated 
with Zulu patients' cultural and health beliefs regarding cancer. The isiZulu word for cancer, umdlavuza, means something that destroys everything or something that cannot be stopped. ${ }^{25}$ Participants further indicated that Zulu patients never asked about prognosis or the odds of surviving. This is in contrast to Western research which showed that most cancer patients wanted some degree of prognostic awareness, ${ }^{6}$ with metastatic cancer patients wanting detailed prognostic information. ${ }^{3}$ Patients' reported tendency to never ask about survival rates is also significantly different from Western trends. ${ }^{3}$ However, most surveys regarding patient preferences for detailed prognostic information have been conducted on English-speaking patients. Little is known about the prognostic communication preferences of ethnically diverse populations. $^{26}$

The HCPs identified a number of challenges that pertained specifically to them. They highlighted competency and training deficits ${ }^{5,27,28}$ and role expectations regarding who communicated prognosis. ${ }^{29}$ Furthermore, HCPs could not agree on whether patients should be given prognostic information. ${ }^{6}$ Reasons for preferring non-disclosure centred on HCPs' discomfort regarding disclosing prognosis $22,24,28,30$ and concerns that prognostic disclosure would result in negative emotional outcomes for patients ${ }^{28,30}$ and would destroy hope. . $^{2,5,31}$ Disclosing a palliative amputation was highlighted as a particular challenge. HCPs preferring prognostic disclosure were concerned about withholding the truth from patients and argued that patients should be truthfully informed of their prognosis. ${ }^{17,28}$ Being clear about the palliative or curative goals of treatment and specifying the outcomes that can be improved by the treatment have been recommended. ${ }^{19}$ There is a lack of evidence that prognostic disclosure resulted in negative emotional outcomes or made patients less hopeful..$^{32}$ In fact, research showed that honesty about prognostic information maintained and sometimes increased hope, even in patients with advanced disease..$^{30}$

HCPs highlighted timing of prognostic information as a challenge given that Zulu patients often went home to discuss treatment options with family decision-makers. HCPs were concerned that they would fixate on the poor prognosis if they were given prognostic information before going home. Prognostic information should, however, be provided when there are requests or expectations that are inconsistent with clinical judgement, ${ }^{19}$ as in this case when patients go home to consult with decision-makers and often delay returning to the hospital. ${ }^{7}$ Furthermore, discussing prognosis facilitates treatment decision-making. ${ }^{19,33}$ Patient knowledge of prognosis has been shown to play a significant role in making appropriate treatment choices. ${ }^{34}$

With regard to disease factors, allied health professionals reported that the unpredictable nature of osteosarcoma complicated the prognostic discussion. As the majority of patients presenting at the study site have metastatic disease, ${ }^{8}$ the progression-free survival rate for these patients is poor and the condition is usually incurable, requiring palliation. ${ }^{35}$ Furthermore, in patients with localised disease, the five-year survival rate is $60-70 \%{ }^{35}$ with a $30-35 \%$ chance of local or systemic recurrence. ${ }^{36}$ There are, therefore, survival and disease progression rates available which the allied health professional staff may not be aware of as they have not been medically trained.

Limitations of the study are that although all those that were eligible to participate were approached, some MDT members were not available at the time of data collection. Secondly, disciplinespecific focus groups were conducted which may have limited interprofessional synergy and data outcomes. Thirdly, the study was conducted in one hospital and focused on a specific cultural group and hence the findings should be seen in context. Lastly, the use of other qualitative data-gathering may have enriched the data.

The study findings provided information on what is said and why it is said; however, further investigation is required to explore how it is said. Deviations from Western research findings emphasised the need for studies exploring prognostic communication in crosscultural encounters. Contextual research on patients' preferences and suggestions on how to communicate about prognosis emerged as a prominent area for future research. Research exploring patients' experience of the proposed strategies would also assist in refining these strategies.

\section{Conclusion}

This paper explored strategies used and challenges faced when communicating about prognosis in this cross-cultural clinical setting. Patients at this study site present late for treatment, and therefore have to receive diagnostic, treatment and prognostic information in close succession or simultaneously. In addition, this cross-cultural clinical setting requires that HCPs integrate cultural beliefs and practices into their management of patients. HCPs proposed strategies for responding to these unique conditions, and they expressed concerns regarding cultural competency, and highlighted a lack of training regarding prognosis communication. However, they proposed strategies that are well documented in the literature. They chose to be innovative and relied on experiential knowledge.

Importantly, various patient, disease and healthcare provider factors that posed challenges to the prognostic communication process were also outlined. HCPs did not necessarily have solutions to these challenges; however, some of the factors highlighted demonstrated participants' sensitivity to cultural aspects of patient care. Furthermore, Zulu patients were reported to respond differently to prognostic information as compared to Western findings. The strategies reported on in this paper will contribute to the evidence-based practice guideline for communicating with Zulu patients diagnosed with osteosarcoma. Our study highlighted the uniqueness of this cross-cultural setting and the need for creative and thoughtful approaches to communicating sensitive information in cross-cultural clinical settings.

\section{Ethics statement}

Prior to commencement of the study ethical approval was obtained from the Biomedical Research Ethics Committee at the University of KwaZulu-Natal, reference no: BE051/15. All procedures were in accordance with the ethical standards of the responsible committee on human experimentation (institutional and national) and with the Helsinki Declaration of 1975, as revised in 2008. Informed written consent was obtained from all patients included in the study.

\section{Declaration}

The authors declare authorship of this article and that they have followed sound scientific research practice. This research is original and does not transgress plagiarism policies

\section{Author contributions}

OB contributed to the conception and design of the work; the acquisition, analysis, and interpretation of data for the work; drafting the work; final approval of the version to be submitted to the journal.

VG contributed to data collection; the analysis and interpretation of data for the work; revising the work critically for important intellectual content; final approval of the version to be published.

RMvR contributed to the conception and design of the work; revising it critically for important intellectual content; final approval of the version to be published.

CA contributed to the conception and design of the work; revising it critically for important intellectual content; final approval of the version to be published.

LCM contributed to the conception and design of the work; revising it critically for important intellectual content; final approval of the version to be published.

\section{ORCID}

Brown O (D) http://orcid.org/0000-0003-2862-1733

Goliath V (iD http://orcid.org/0000-0003-0044-8318

Van Rooyen RM (iD) http://orcid.org/0000-0002-6019-6602

Aldous C (D) http://orcid.org/0000-0002-7199-9160

Marais LC (D) http://orcid.org/0000-0002-1120-8419 


\section{References}

1. Robinson TM, Alexander SC, Hays M, Jeffreys MC, Olson MK, Rodrigues KL, et al. Patient-oncologist communication in advanced cancer: predictors of patient perception of prognosis. Support Care Cancer. 2008;16(9):1049-57. https://www.ncbi.nlm. nih.gov/pubmed/18196288

2. Back AL, Anderson WG, Bunch L, Marr LA, Wallace JA, Yang HB, Arnold RM. Communication about cancer near the end of life. Cancer Supplement. 2008;113(7):1897-10. https://www.ncbi.nlm. nih.gov/pubmed/18798531

3. Hagerty RG, Butow PN, Ellis PM, Lobb EA, Pendlebury S, Leigh N, Goldstein D, Lo SK, Tattersall MH. (2004). Cancer patient preferences for communication of prognosis in the metastatic setting. J Clin Oncol. 2004;22(9):1721-30. https://www.ncbi.nlm. nih.gov/pubmed/15117995

4. Lamont EB, Christakis NA. Complexities in prognostication in advanced cancer: "To help them live their lives the way they want". JAMA. 2003;290(1):98-104. https://jamaevidence.mhmedical.com/ content.aspx? bookid $=846 \&$ sectionid $=61351459$

5. Russell BJ, Ward AM. Deciding what information is necessary: do patients with advanced cancer want to know all the details? Cancer Manag Res. 2011;3:191-99. https://www.ncbi.nlm.nih.gov/ pmc/articles/PMC3139480/

6. Innes S, Payne S. Advanced cancer patients' prognostic information preferences: A review. Palliative Medicine. 2009;23:2939. https://journals.sagepub.com/doi/10.1177/0269216308098799

7. Brown O, Goliath V, Van Rooyen DRM, Aldous C, Marais LC. Cultural factors that influence the treatment of osteosarcoma in Zulu patients: Healthcare professionals' perspectives and strategies. Health SA Gesondheid. 2018;23(0):a1095. https://hsag. co.za/index.php/hsag/article/view/1095

8. Ferreira N, Marais LC. Osteosarcoma presentation stages at a tumour unit in South Africa. S Afr Med J. 2012;102(8):673-76. http://www.samj.org.za/index.php/samj/article/view/5835/4358

9. Back AL, Arnold RM. Discussing prognosis: "How much do you want to know?" talking to patients who are prepared for explicit information. J Clin Oncol. 2006;24(25):4209-13. https://www.ncbi. nlm.nih.gov/pubmed/16943539

10. Ngo-Metzger Q, August KJ, Srinivasan M, Liao S, Meyskens FL Jr. End-of-Life care: guidelines for patient-centered communication. Am Fam Physician. 2008;77(2):167-74. https://www.ncbi.nlm.nih. gov/pubmed/18246886

11. Delvecchio Good M, Good BJ, Schaffer C, Lind SE. American oncology and the discourse on hope. Cult Med Psychiatry. 1990;14(1):59-79. https://www.ncbi.nlm.nih.gov/pubmed/2340733

12. Braun V, Clarke V. Using thematic analysis in psychology. Qual Res Psychol. 2006;2:77-101. https://www.tandfonline.com/doi/ abs/10.1191/1478088706qp063oa

13. Lincoln Y, Guba E. Naturalistic inquiry. New York (NY): Sage; 1985.

14. Shenton AK. Strategies for ensuring trustworthiness in qualitative research. Education for Information, 2004;22:63-75. https://eric. ed.gov/?id=EJ792970

15. De Laine M. Fieldwork, participation and practice: ethics and dilemmas in qualitative research. London (UK): Sage; 2000.

16. Sinclair CT. Communicating prognosis in advanced cancer. $J$ Support Oncol. 2006;4(4):201-204. https://www.mdedge.com/ sites/default/files/jso-archives/Elsevier/jso/journal/articles/0404201. pdf

17. Wenrich MD, Curtis JR, Shannon SE, Carline JD, Ambrozy DM, Ramsey PG. Communicating with dying patients within the spectrum of medical care from terminal diagnosis to death Arch Intern Med. 2001;161(6):868-74. https://jamanetwork.com/ journals/jamainternalmedicine/fullarticle/647723

18. Daugherty CK. Hlubocky FJ. What are terminally ill cancer patients told about their expected deaths? A study of cancer physicians' self-reports of prognosis disclosure. J Clin Oncol. 2008;26(36):5988-93. https://www.ncbi.nlm.nih.gov/pmc/articles/ PMC2645114

19. Clayton JM, Hancock KM, Butow PN, Tattersall MH, Currow DC, Australian and New Zealand Expert Advisory Group, et al. Clinical practice guidelines for communicating prognosis and end-of-life issues with adults in the advanced stages of a life-limiting illness, and their caregivers. Med J Aust, 2007;186(12):S77-S108. https:// www.mja.com.au/journal/2007/186/12/clinical-practice-guidelinescommunicating-prognosis-and-end-life-issues-adults
20. Back AL, Arnold RM, Baile WF, Tulsky JA, Fryer-Edwards K. Approaching difficult communication tasks in oncology. $C A$ Cancer J Clin. 2005;55:164-77. https://onlinelibrary.wiley.com/doi/ full/10.3322/canjclin.55.3.164

21. Clayton JM, Butow PN, Arnold RM, Tattersall, MH. Fostering coping and nurturing hope when discussing the future with terminally ill cancer patients and their caregivers. Cancer. 2005;103:1965-75. https://onlinelibrary.wiley.com/doi/full/10.1002/ cncr.21011

22. Baile WF, Buckman AR, Lenzi BR, Glober G, Beale EA, Kudelka AP. SPIKES-A six-step protocol for delivering bad news: application to the patient with cancer. Oncologist, 2000;5:302-11. http:// theoncologist.alphamedpress.org/content/5/4/302.full.pdf

23. Barclay JS, Blackhall LJ, Tulsky JA. Communication strategies and cultural issues in the delivery of bad news. J Palliat Med. 2007;10(4):8-977. https://www.liebertpub.com/doi/10.1089/ jpm.2007.9929

24. Kirk P, Kirk I, Kristjanson LJ. What do patients receiving palliative care for cancer and their families want to be told? A Canadian and Australian qualitative study. BMJ, 2004;328:1343. https://www.bmj. com/content/328/7452/1343/related

25. Brown O, Goliath V, Van Rooyen DRM, Aldous C, Marais LC. Strategies and challenges for communicating the diagnosis of cancer in cross-cultural clinical settings-perspectives from South African healthcare professionals. J Psychsoc Oncol. 2017; DOI: 10.1080/07347332.2017.1329767 https://www.tandfonline.com/ doi/abs/10.1080/07347332.2017.1329767

26. Mitchison $D$, Butow $P$, Sze $M$, Aldridge $L$, Hui R, Vardy J, Eisenbruch M, ledema R, Goldstein D. Prognostic communication preferences of migrant patients and their relatives. Psychooncology. 2012;21(5):496-504. https://onlinelibrary.wiley. com/doi/abs/10.1002/pon.1923

27. Butow PN, Dowsett S, Hagerty R, Tattersall MH. Communicating prognosis to patients with metastatic disease: What do they really want to know? Support Care Cancer, 2002;10(2):161-68. https:// www.ncbi.nlm.nih.gov/pubmed/11862506

28. Hancock K, Clayton JM, Parker SM, Wal der S, Butow PN, Carrick $\mathrm{S}$, et al. Truth-telling in discussing prognosis in advanced life-limiting illnesses: a systematic review. Palliative Medicine. 2007;21(6):507-17. https://journals.sagepub.com/ doi/10.1177/0269216307080823

29. Reinke LF, Shannon SE, Engelberg RA, Young JP, Curtis JR. Supporting hope and prognostic information: nurses' perspectives on their role when patients have life-limiting prognoses. J Pain Symptom Manage. 2010;39(6):982-92. https://www.ncbi.nlm.nih. gov/pubmed/20538182

30. Mack JW, Smith TJ. Reasons why physicians do not have discussions about poor prognosis, why it matters and what can be improved. J Clin Oncol. 2012;30(22):2715-17. https://jhu.pure. elsevier.com/en/publications/reasons-why-physicians-do-not-havediscussions-about-poor-prognos-3

31. Finlay E, Cassarett D. Making difficult discussions easier: using prognosis to facilitate transitions to hospice. CA Cancer J Clin. 2008;59:250-63. https://onlinelibrary.wiley.com/doi/pdf/10.3322/ caac.20022

32. Mack JW, Wolfe J, Cook EF, Grier HE, Cleary PD, Weeks JC. Hope and prognostic disclosure. J Clin Oncol. 2007;25(35):5636-42. https://www.ncbi.nlm.nih.gov/pubmed/18065734

33. Cartwright LA, Dumenci L, Siminoff LA, Matsuyama RK. Cancer patients' understanding of prognostic information. $J$ Cancer Ed. 2014;29(2):311-17. https://www.ncbi.nlm.nih.gov/ pubmed/24402976

34. Weeks JC, Cook EF, O'Day SJ, Peterson LM, Wenger N, Reding $\mathrm{D}$, et al. Relationship between cancer patients' predictions of prognosis and their treatment preferences. JAMA, 1998;279:170914. https://jamanetwork.com/journals/jama/fullarticle/187594

35. Errani C, Longhi A, Rossi G, Rimondi E, Biazzo A, Toscano A, et al. Palliative therapy for osteosarcoma. Expert Rev Anticancer Ther. 2011;11:217-27. https://www.tandfonline.com/doi/abs/10.1586/ era.10.172

36. Bacci G, Briccoli A, Longhi A, Ferrari S, Mercuri M, Faggioli F, et al. Treatment and outcome of recurrent osteosarcoma: experience at Rizzoli in 235 patients initially treated with neoadjuvant chemotherapy. Acta Oncol. 2005;44(7):748-55. https://www. tandfonline.com/doi/full/10.1080/0284186050032750 